\title{
Efeito de extratos vegetais aplicado em solo sobre Sclerotinia sclerotiorum e sobre feijoeiro comum
}

\author{
Cláudia de Souza Zanella ${ }^{1}$, Walber Luiz Gavassoni ${ }^{2}$, Lilian Maria Arruda Bacchi ${ }^{2}$, Anelise Samara Nazari Formagio²
}

${ }^{1}$ Universidade Estadual de Mato Grosso do Sul (UEMS), CEP: 79804-970, Dourados, MS, Brasil. ${ }^{2}$ Faculdade de Ciências Agrárias, Universidade Federal da Grande Dourados (UFGD), CEP: 79.804-970, Dourados, MS, Brasil.

Autor para correspondência: Cláudia de Souza Zanella (clauzaza@gmail.com)

Data de chegada: 06/05/2016. Aceito para publicação em: 14/07/2017.

$10.1590 / 0100-5405 / 2187$

\section{RESUMO}

Zanella, C.S.; Gavassoni, W.L.; Bacchi, L.M.A.; Formagio, A.S.N.Efeito de extratos vegetais aplicado em solo sobre sclerotinia sclerotiorum e sobre feijoeiro comum. Summa Phytopathologica, v.44, n.2, p.156-163, 2018.

O patógeno Sclerotinia Sclerotiorum pode atacar mais de 400 espécies de plantas, como batata, soja, girassol, entre outras. Objetivou-se identificar a proporção solo:areia mais adequada para a germinação carpogênica de escleródios de S. sclerotiorum, avaliar o efeito de extratos vegetais e suas frações sobre a germinação carpogênica do patógeno e sobre plantas de feijoeiro. Para os experimentos de identificação da melhor proporção solo:areia, calculou-se a porcentagem de germinação carpogênica. Para a avaliação do efeito de extratos vegetais e frações sobre escleródios, estes foram aplicados no dia da instalação do ensaio e 30 dias após a instalação do ensaio no substrato solo:areia (1:1) infestado com escleródios. Para avaliar o efeito dos extratos vegetais e frações sobre feijoeiro, os extratos vegetais foram aplicados via pulverização sobre as plantas, aos 30 dias após a semeadura. Os escleródios apresentaram maior germinação carpogênica na proporção 1:1 e 1:2 do substrato solo:areia. Houve menor germinação carpogênica sob a fração acetato de etila de ervilhaca e fração acetato de etila de S. terebinthifolius, quando estes foram aplicados aos 30 dias após a instalação do ensaio. Os extratos não apresentaram fitotoxicidade ao feijoeiro.

Palavras-chave: Mofo-branco, controle alternativo, escleródios.

\section{ABSTRACT}

Zanella, C.S.; Gavassoni, W.L.; Bacchi, L.M.A.; Formagio, A.S.N. Efect of plant extracts applied in soil on sclerotinia sclerotiorum and common bean plants. Summa Phytopathologica, v.44, n.2, p.156-163, 2018.

The pathogen Sclerotinia sclerotiorum can attack over 400 plant species such as potatoes, soybeans and sunflowers. This study aimed to identify the most adequate soil:sand proportion for the carpogenic germination of S. sclerotiorum sclerotia, as well as to evaluate the effect of plant extracts and their fractions on the carpogenic germination of sclerotia and on common bean plants. To identify the most adequate soil:sand proportion, the percentage of carpogenic germination was calculated. To evaluate the effect of plant extracts and fractions on sclerotia, the extracts and fractions were applied on the day the experiment was installed and after 30 days in soil:sand (1:1) substrate infested with sclerotia. To evaluate the effect of plant extracts and fractions on bean plants, the plant extracts were sprayed on plants at 30 days after sowing. Sclerotia showed greater carpogenic germination at 1:1 and 1:2 soil:sand substrate proportions. There was lower carpogenic germination for the ethyl acetate fraction obtained from vetch and the ethyl acetate fraction from S. terebinthifolius when applied at 30 days after the experiment was installed. The extracts did not present phytotoxicity to bean plants.

Keywords: White mold, alternative control, sclerotia.

A germinação carpogênica dos escleródios de Sclerotinia sclerotiorum (Lib.) de Bary pode ser suprimida por resíduos de diferentes culturas e também por diferentes extratos vegetais $(10,15$, 16). Garcia et al. (6) verificaram que o óleo de nim indiano (Azadirachta indica) inibiu o crescimento micelial de $S$. sclerotiorum, mas esse efeito foi maior quando foi associado ao óleo de karanja (Pongamia glabra) demonstrando o efeito sinérgico entre os óleos, e que extratos de folhas de Santa Bárbara (Melia azedarach L.), mentrasto (Ageratum conyzoides L.), arruda (Ruta graveolens L.) e pimenta longa (Piper aduncum L.) inibiram em média $25 \%$ do crescimento micelial, e o extrato de frutos de pimenta longa inibiu em média $43 \%$ do crescimento micelial.

Óleos essenciais de Baccharis trimera e Salva officinalis, nas concentrações de $0,15 \%, 0,20 \%$ e Cymbopogom citratus, a partir da concentração de $0,01 \%$, inibiram o crescimento micelial de $S$. sclerotiorum (13). Os óleos de Origanum syriacum var bevanii e Foeniculum vulgare apresentaram inibição total do crescimento micelial do patógeno, a partir das concentrações de $3,2 \mu \mathrm{g} / \mathrm{ml}$ e $1,6 \mu \mathrm{g} / \mathrm{ml}$, respectivamente (19). Plantas nativas do cerrado tiveram seu efeito comprovado in vitro contra S. sclerotiorum, a exemplo de Annona sp. (16) e Xylopia sp. (1). Extratos e frações de plantas cultivadas, como milho, trigo, aveia, ervilhaca e feijão também apresentam efeito negativo na germinação carpogênica de $S$. sclerotiorum (15). O efeito de extratos e óleos vegetais é muito estudado em relação ao crescimento micelial do patógeno, entretanto são escassos os trabalhos relativos à germinação carpogênica dos escleródios.

É evidente a atividade fungicida de compostos presentes em extratos vegetais, entretanto, alguns compostos, como o extrato de nim, podem apresentar fitotoxicidade quando em altas concentrações, dependendo da espécie, idade e fase de desenvolvimento da planta (11).

O estudo dos efeitos alelopáticos de plantas sobre o estabelecimento (germinação e crescimento inicial) de feijoeiro tem sido objeto de estudo de vários autores, entretanto, poucos estudos são conduzidos para verificar a ação de extratos vegetais sobre a cultura estabelecida. 
Nesse contexto, objetivou-se, no presente trabalho, identificar a proporção de solo e areia mais adequada para a germinação carpogênica de escleródios de $S$. sclerotiorum, pois diferentes substratos podem estimular ou suprimir a germinação carpogênica (14) e avaliar o efeito de extratos vegetais e frações resultantes do particionamento de extratos vegetais, aplicados ao substrato, sobre a germinação carpogênica de patógeno e sobre o feijoeiro comum.

\section{MATERIAL E MÉTODOS}

Identificação da proporção solo:areia mais adequada para a germinação carpogênica e avaliação da germinação carpogênica sob extratos vegetais

Foram realizados seis ensaios no Laboratório de Microbiologia Agrícola e Fitopatologia da Faculdade de Ciências Agrárias da Universidade Federal da Grande Dourados (UFGD), no período de julho de 2009 a setembro de 2012, sendo um para identificar a proporção solo:areia mais apropriada para a germinação carpogênica e cinco para avaliar a germinação carpogênica de escleródios de S. sclerotiorum sob extratos vegetais aplicados ao solo.

\section{Obtenção, multiplicação e manutenção do inóculo}

Os isolados de $S$. sclerotiorum foram obtidos em área naturalmente infestada pelo patógeno no município de Chapadão do Sul, MS. Os escleródios foram produzidos a partir da repicagem do micélio do fungo para erlenmeyers contendo discos de cenoura previamente autoclavados e os frascos foram incubados a $25^{\circ} \mathrm{C}$, em escuro pleno, por aproximadamente 30 dias. Após esse período, os escleródios formados foram retirados dos frascos, lavados em água corrente e armazenados a $5^{\circ} \mathrm{C}$ até a utilização dos mesmos nos experimentos.

\section{Delineamento experimental e análise de dados}

Todos os ensaios foram realizados em delineamento inteiramente casualizado e cada unidade experimental foi constituída por uma caixa tipo gerbox contendo 20 escleródios. Os dados de germinação carpogênica (\%) foram transformados em arco seno $\sqrt{ }(\mathrm{x}+1) / 100$, e os demais dados foram transformados em $\sqrt{ } \mathrm{x}+1$, para análise de variância e comparação entre as médias pelo teste de Tukey a 5\% de probabilidade, com o auxílio do programa SISVAR. Os dados de germinação carpogênica foram submetidos à análise de regressão entre o tempo de incubação (dias) como fator independente e a germinação carpogênica (\%) como variável dependente para os extratos testados.

\section{Espécies vegetais}

Folhas da espécie vegetal Annona cacans foram coletadas próximo a cidade de Dourados, MS. Folhas da espécie vegetal Palicourea crocea foram coletadas no Parque Ivinhema, no município de Ivinhema, MS. Folhas da espécie vegetal Schinus terebinthifolius foram coletados no Horto de Plantas Medicinais da UFGD, no município de Dourados, MS. Estas espécies foram identificadas e as exsicatas $A$. cacans (DDMS 3818), P. crocea (DDMS 4448) e S. terebinthifolius (DDMS 4602) encontram-se depositadas no Herbário da Faculdade de Ciências Biológicas e Ambientais - FCBA/UFGD. Folhas das espécies cultivadas aveia (Avena sativa L.), ervilhaca (Vicia sativa L.), feijão (Phaseolus vulgaris L.) e trigo (Triticum aestivum L.) foram coletadas na Fazenda Experimental da Faculdade de Ciências Agrárias da UFGD, em Dourados, MS.

\section{Preparação e fracionamento das espécies vegetais}

O material vegetal de $A$. cacans, $P$. crocea e $S$. terebinthifolius foi desidratado em estufa de ar circulante à temperatura de $55^{\circ} \mathrm{C}$ e triturado em moinho de facas. $\mathrm{O}$ extrato metanólico foi obtido por maceração exaustiva com metanol. O material vegetal das espécies cultivadas foi desidratado por $48 \mathrm{~h}$ em estufa com circulação de ar e temperatura de $55^{\circ} \mathrm{C}$ e triturado em moinho elétrico. O extrato etanólico foi obtido por percolação com etanol, a frio, por cinco dias. Os extratos foram submetidos à particionamento líquido-líquido, com os solventes de polaridade crescentes hexano, diclorometano, clorofórmico e acetato de etila, que com posterior evaporação dos solventes em rota evaporador resultaram nas frações hexânica, diclorometânica, clorofórmica e acetato de etila.

\section{Experimento 1}

Para a identificação da proporção solo:areia mais adequada para a germinação carpogênica, foram testados seis tratamentos (solo; areia; solo e areia na proporção $1: 1$; solo e areia na proporção $2: 1$; solo e areia na proporção $1: 2$ e a testemunha ágar-água), com 10 repetições. O solo, coletado na área da UFGD, e a areia foram esterilizados por três dias consecutivos por 1 hora a temperatura de $120^{\circ} \mathrm{C}$. Uma camada de aproximadamente $2 \mathrm{~cm}$ do substrato foi acondicionada em caixas tipo gerbox $(11,5 \times 11,5 \times 3,5 \mathrm{~cm})$ e umedecida com $10 \mathrm{~mL}$ de água esterilizada. Após a distribuição de 20 escleródios sobre o substrato, as caixas tipo gerbox foram lacradas e incubadas a $18^{\circ} \mathrm{C}$ com fotoperíodo de $12 \mathrm{~h}$ luz/12h escuro até o final do experimento. As avaliações iniciaram-se a partir da verificação da emissão de estipes, onde foi enumerado o número total de escleródios com emissão de estipes e de apotécios e o número total de estipes e de apotécios por unidade experimental. Com base no número de escleródios com apotécios, foi calculada a porcentagem de germinação carpogênica. Foi considerada germinação carpogênica a formação de apotécios pelo escleródio.

\section{Experimento 2}

Para a avaliação do efeito de extratos vegetais e suas frações aplicados no substrato solo:areia $(1: 1)$ sobre a germinação carpogênica de escleródios, foram realizados 6 ensaios. A aplicação dos extratos e frações ocorreu no dia da instalação do experimento, quando foi realizada a infestação do substrato ou 30 dias de instalação do experimento (considerados como 0 d.i. e 30 d.i). Os tratamentos e repetições estão descritos na Tabela 1 . O substrato, esterilizado conforme descrito anteriormente, após ser acondicionado em caixas tipo gerbox e umedecido a $70 \%$ da capacidade de campo, foi infestado com 20 escleródios. A capacidade de campo do substrato foi verificada através do método do anel volumétrico com uso da mesa de tensão para determinar a macro e microporosidade do substrato, onde as amostras foram submetidas a uma tensão de $6 \mathrm{Kpa}$, por $24 \mathrm{~h}$, sendo necessário adicionar $0,25 \mathrm{~mL}$ de água para cada $1 \mathrm{~g}$ de substrato, para que o substrato atingisse $70 \%$ da capacidade de campo.

Os extratos e frações foram dissolvidos em tubos de ensaio contendo água esterilizada e autoclavada. Após agitação dos tubos em agitador Vortex para a dissolução dos extratos, $10 \mathrm{~mL}$ da solução foi aplicada sobre os escleródios com o auxílio de um atomizador DeVilbiss (número 15) acoplado a um aspirador/compressor Fanem (modelo C.A.). A concentração final dos extratos foi de $1000 \mu \mathrm{g} / \mathrm{mL}$ e das frações de $100 \mu \mathrm{g} / \mathrm{mL}$. As avaliações foram realizadas conforme descrito anteriormente.

Avaliação de extratos vegetais sobre feijoeiro comum

Houve dois ensaios, em casa de vegetação, com a cultivar IAPAR 
Tabela 1. Ensaios realizados para avaliar a germinação carpogênica de escleródios de S. sclerotiorum sob extratos etanólicos e metanólicos e frações de espécies vegetais.

\begin{tabular}{|c|c|c|c|}
\hline Ensaio & Tratamentos & Repetições & Aplicação (dias de incubação) \\
\hline 1 & $\begin{array}{l}\text { Ervilhaca - fração acetato de etila } \\
\text { Aveia - fração hexânica } \\
\text { Feijão - fração hexânica } \\
\text { Trigo - fração diclorometânica } \\
\text { Aveia - fração acetato de etila } \\
\text { Testemunha }\end{array}$ & 15 & 0 \\
\hline 3 & $\begin{array}{l}\text { P. crocea } \\
\text { P. crocea - fração hexânica } \\
\text { P. crocea - fração clorofórmica } \\
\text { P. crocea - fração acetato de etila } \\
\text { A. cacans } \\
\text { A, cacans - fração clorofórmica } \\
\text { A. cacans - fração acetato de etila } \\
\text { S. terebinthifolius } \\
\text { S. terebinthifolius - fração acetato de etila } \\
\text { Testemunha } \\
\left.\text { Fungicida (i.a. Procimidone } 150 \mathrm{~g} 100 \mathrm{~L}^{-1}\right)^{*}\end{array}$ & 5 & 0 \\
\hline 4 & $\begin{array}{l}\text { P. crocea } \\
\text { P. crocea - fração hexânica } \\
\text { P. crocea - fração clorofórmica } \\
\text { P. crocea - fração acetato de etila } \\
\text { A. cacans } \\
\text { A. cacans - fração acetato de etila } \\
\text { S. terebinthifolius } \\
\text { S. terebinthifolius - fração clorofórmica } \\
\text { S. terebinthifolius - fração acetato de etila } \\
\text { Testemunha } \\
\left.\text { Fungicida (i.a. Procimidone } 150 \mathrm{~g} 100 \mathrm{~L}^{-1}\right)^{*}\end{array}$ & 5 & 0 \\
\hline 5 & $\begin{array}{l}\text { P. crocea } \\
\text { P. crocea - fração hexânica } \\
\text { P. crocea - fração clorofórmica } \\
\text { P. crocea - fração acetato de etila } \\
\text { A. cacans } \\
\text { A. cacans - fração clorofórmica } \\
\text { A. cacans - fração acetato de etila } \\
\text { S. terebinthifolius } \\
\text { S. terebinthifolius - fração clorofórmica } \\
\text { S. terebinthifolius - fração acetato de etila } \\
\text { Testemunha } \\
\left.\text { Fungicida (i.a. Procimidone } 150 \mathrm{~g} 100 \mathrm{~L}^{-1}\right)^{*}\end{array}$ & 10 & 30 \\
\hline
\end{tabular}

* Concentração de 75 g i.a. $\mathrm{L}^{-1}$

81 e a cultivar IPR Siriri, respectivamente, ambas de crescimento indeterminado, entre julho e outubro de 2012.

Foram utilizadas bandejas de polietileno $(48 \times 29 \times 9 \mathrm{~cm})$ contendo $5,8 \mathrm{~kg}$ de latossolo vermelho distroférrico, adubado com a fórmula 00 20-20. Realizou-se a semeadura em quatro linhas empregando-se 14 sementes, previamente tratadas com a mistura Carbendazim + Thiram
(200 ml p.c. $100^{-1} \mathrm{~kg}$ de sementes). Após a emergência foi realizado o desbaste, mantendo-se oito plantas por linha. Para a avaliação, foram consideradas as quatro plantas centrais de cada linha. Cada bandeja representava duas parcelas. A irrigação era realizada a cada dois dias com 1 litro de água por bandeja. A semeadura ocorreu em julho de 2012 (primeiro ensaio) e setembro de 2012 (segundo ensaio). 
Os tratamentos constaram da pulverização dos extratos metanólicos de $S$. terebinthifolius, $P$. crocea e $A$. cacans e as frações clorofórmica de $P$. crocea e clorofórmica e acetato de etila de $S$. terebinthifolius. No segundo ensaio foi adicionado o tratamento óleo essencial de $S$. terebinthifolius. Na testemunha utilizou-se somente água. A concentração dos extratos foi de $1000 \mu \mathrm{g} / \mathrm{mL}$ para os extratos metanólicos e o óleo essencial e de $100 \mu \mathrm{g} / \mathrm{mL}$ para as frações.

Aos 30 dias após a semeadura os extratos metanólicos e as frações foram misturados em $100 \mathrm{~mL}$ de água destilada e posteriormente aplicados sobre todas as plantas da parcela, utilizando um pulverizador manual com gatilho para garrafa PET. As espécies vegetais utilizadas e a preparação do material estão descritas em 2.1.3 e 2.1.4.

As variáveis analisadas foram altura de planta, medindo-se a distância da superfície do solo até o ápice das plantas; número de folíolos por planta e fitotoxicidade. A fitotoxicidade foi avaliada aos 37 dias após a semeadura, adotando-se a escala de avaliação visual de Frans (1972), que varia de 1 a 9, onde 1 significa ausência de sintoma e 9 morte da planta, conforme descrito por Fontes et al. (5).

O delineamento estatístico foi o de blocos casualizados, com três repetições. Os dados obtidos foram submetidos à analise de variância e os tratamentos comparados através do teste de Tukey, ao nível de 5\% de probabilidade pelo programa SISVAR.

\section{RESULTADOS E DISCUSSÃO}

\section{Proporção solo:areia mais adequada para a germinação carpogênica}

No experimento para identificação da proporção solo e areia mais adequada para a germinação carpogênica dos escleródios, observou-se a emissão de estipes em todos os tratamentos após 36 dias de incubação (DI), com exceção dos substratos solo e solo:areia (2:1). Não foi observada formação de apotécios em nenhum dos tratamentos naquela avaliação. O maior número de escleródios com emissão de estipes foi observado no tratamento ágar-água. Nas avaliações subseqüentes, o número de escleródios que apresentaram emissão de estipes foi maior nos tratamentos solo e areia (1:1) e solo e areia (1:2) (dados não apresentados). Os dados de germinação carpogênica foram submetidos à análise de regressão entre o tempo de incubação e a germinação carpogênica (\%). Para todos os tratamentos, houve aumento linear da germinação carpogênica com o tempo de incubação (Figura 1).

$\mathrm{Na}$ avaliação realizada aos 43 DI os substratos solo, solo:areia (2:1) e solo:areia (1:1) apresentaram o menor número de escleródios com emissão de apotécios. Nesta avaliação, a germinação carpogênica foi maior no tratamento ágar-água (27\%), entretanto, nas avaliações

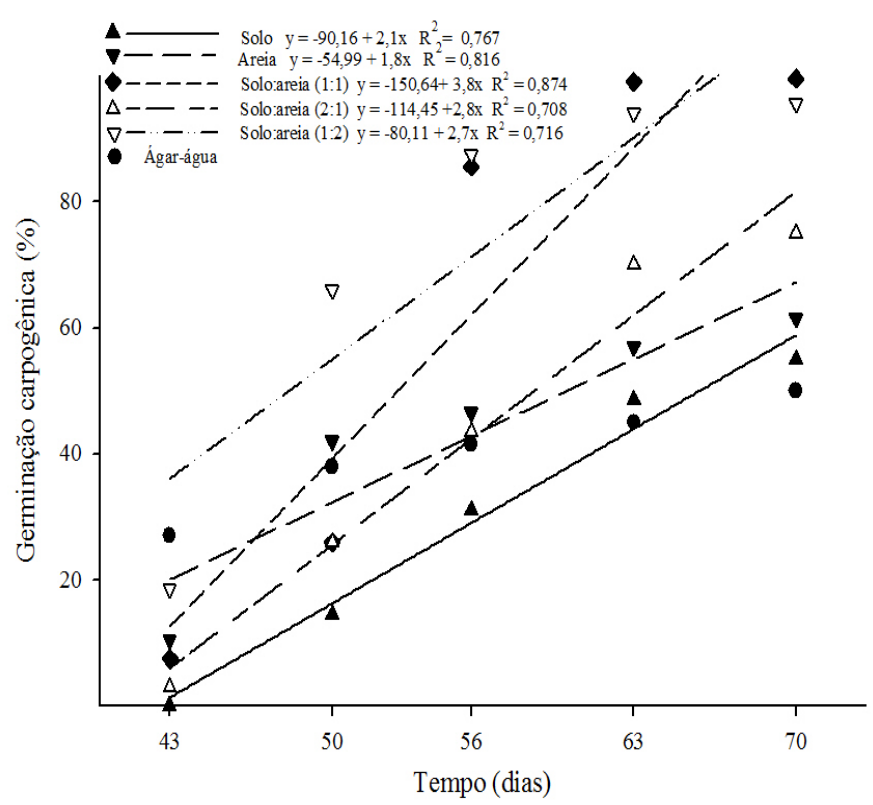

Figura 1. Germinação carpogênica (\%) de escleródios de $S$. sclerotiorum sob diferentes substratos em função do tempo (dias), após a incubação.

seguintes, este tratamento apresentou menor germinação carpogênica, comparado a outros tratamentos, indicando que, nas condições deste experimento, o meio ágar-água proporciona um maior número de apotécios no início da incubação, mas com o passar do tempo, a velocidade da formação de apotécios tende a diminuir, quando comparada aos demais tratamentos (Tabela 2).

A partir das avaliações realizadas aos 56 DI, as misturas solo e areia (1:1) e (1:2) apresentaram a maior germinação. Aos 70 DI, apenas 50\% dos escleródios em ágar-água apresentavam germinação carpogênica, contra $98,6 \%$ e $94,6 \%$ dos tratamentos solo e areia nas proporções $1: 1$ e 1:2, respectivamente.

O substrato ágar-ágar não proporcionou maior porcentagem de germinação neste trabalho, entretanto em trabalho realizado por Reis et al. (14), a maior porcentagem de germinação carpogênica foi observado em ágar-ágar (89\%), ao lado de areia grossa e vermiculita. Monteiro et al. (10) observaram que a mistura solo e areia na proporção 1:1 foi o substrato que apresentou maior porcentagem de escleródios germinados $(100 \%)$, confirmando o resultado encontrado no presente trabalho.

Tabela 2. Germinação carpogênica (\%) de escleródios de S. sclerotiorum sob diferentes substratos aos 43, 50, 56, 63 e 70 dias de incubação.

\begin{tabular}{|c|c|c|c|c|c|}
\hline \multirow[b]{2}{*}{ Substratos } & \multicolumn{5}{|c|}{ Germinação carpogênica (\%) } \\
\hline & \multicolumn{5}{|c|}{ Dias de incubação } \\
\hline Solo & $1 \mathrm{~b}$ & $15 \quad \mathrm{c}$ & $31 \mathrm{~b}$ & $49 \quad \mathrm{~cd}$ & $55 \quad \mathrm{~cd}$ \\
\hline Solo e areia (1:1) & $8 \mathrm{~b}$ & $26 \mathrm{bc}$ & 86 a & 98 a & 99 a \\
\hline Solo e areia (2:1) & $3 \mathrm{~b}$ & $26 \mathrm{bc}$ & $44 \mathrm{~b}$ & $70 \quad b c$ & 75 bc \\
\hline Ágar-água & $27 \mathrm{a}$ & $38 \mathrm{bc}$ & $42 \mathrm{~b}$ & 45 & 50 \\
\hline CV (\%) & 46,9 & 39,4 & 63,0 & 32,3 & 33,2 \\
\hline
\end{tabular}

Médias seguidas pela mesma letra na coluna, não diferem entre si pelo teste de Tukey a $5 \%$ de probabilidade. 
Avaliação da germinação carpogênica de escleródios de $S$. sclerotiorum

Nos ensaios em que as frações dos extratos de plantas foram aplicados no substrato infestado, observou-se que quando estas foram aplicadas no dia da instalação do ensaio, não houve diferença significativa na germinação carpogênica dos escleródios.

Quando a aplicação ocorreu 30 dias após a instalação do ensaio, as frações acetato de etila de ervilhaca e de aveia proporcionaram menor germinação carpogênica em relação à fração hexânica de aveia, aos 37 dias após a incubação. Aos 49 dias após incubação, a fração acetato de etila de ervilhaca proporcionou menor germinação carpogênica em relação às frações hexânica de aveia e de feijão e em relação à testemunha. Já aos 56 dias após incubação, sob a fração acetato de etila de ervilhaca, a germinação carpogênica menor, quando comparada à testemunha ou à fração hexânica de feijão. A inibição foi de 39 e 30\%, em relação à testemunha para as avaliações realizadas aos 49 e 56 DI, respectivamente (Tabela 3). Esta diferença em função da época da aplicação dos extratos pode ser devido à aplicação ser mais próxima à época de germinação dos escleródios, pois em todos os ensaios a emissão de apotécios ocorreu próximo aos 30 dias de incubação dos mesmos. Em trabalho conduzido por Silva et al. (15), todas as frações utilizadas no presente ensaio afetaram negativamente a germinação carpogênica de escleródios de S. sclerotiorum em todas as épocas de avaliação, entretanto, tal trabalho foi conduzido em ágar-água. Tais resultados sugerem que o comportamento dos compostos presentes nos extratos e frações sobre a germinação carpogênica de escleródios pode ser diferente em função do substrato utilizado.

No primeiro ensaio, realizado com extratos vegetais e suas frações aplicados no dia da instalação do ensaio, apenas na avaliação realizada aos 44 DI (Tabela 4) houve diferença entre os tratamentos. A germinação carpogênica dos escleródios sob o extrato de $P$. crocea foi menor em relação à sua fração hexânica e às frações clorofórmica e acetato de etila de $S$. terebinthifolius.

São escassos os trabalhos relacionados ao efeito de extratos de $P$. crocea sobre patógenos, entretanto existem relatos da ação inseticida de $P$. marcgravii (8).

Este ensaio foi repetido, sem a fração clorofórmica de $A$. cacans, porém, em nenhuma das avaliações foi verificada diferença entre os tratamentos. Na primeira avaliação, realizada aos $28 \mathrm{DI}$, todos os tratamentos já apresentavam estipes, mas nenhum deles apresentava formação de apotécios. Somente na segunda avaliação, realizadas aos

Tabela 3. Germinação carpogênica (\%) de escleródios de $S$. sclerotiorum sob frações de extratos de plantas cultivadas, aplicadas aos 30 dias após instalação do ensaio, aos 37, 49, 56 dias de incubação

\begin{tabular}{|c|c|c|c|}
\hline \multirow{3}{*}{ Partição } & \multicolumn{3}{|c|}{ Germinação carpogênica (\%) } \\
\hline & \multicolumn{3}{|c|}{ Dias de incubação } \\
\hline & 37 & 49 & 56 \\
\hline Aveia - acetato de etila & 6 & $72 \mathrm{ab}$ & $83 \mathrm{abc}$ \\
\hline Ervilhaca - acetato de etila & $8 \mathrm{~b}$ & $54 \quad \mathrm{~b}$ & $66 \quad c$ \\
\hline Testemunha & $14 \mathrm{ab}$ & $88 \quad \mathrm{a}$ & $93 \mathrm{ab}$ \\
\hline CV (\%) & 77,9 & 17,3 & 13,0 \\
\hline
\end{tabular}

Médias seguidas pela mesma letra na coluna, não diferem entre si pelo teste de Tukey a $5 \%$ de probabilidade.

Tabela 4. Germinação carpogênica (\%) de escleródios de S. sclerotiorum sob extratos e frações de extratos vegetais, aplicados no dia da instalação do ensaio, aos 44 dias de incubação

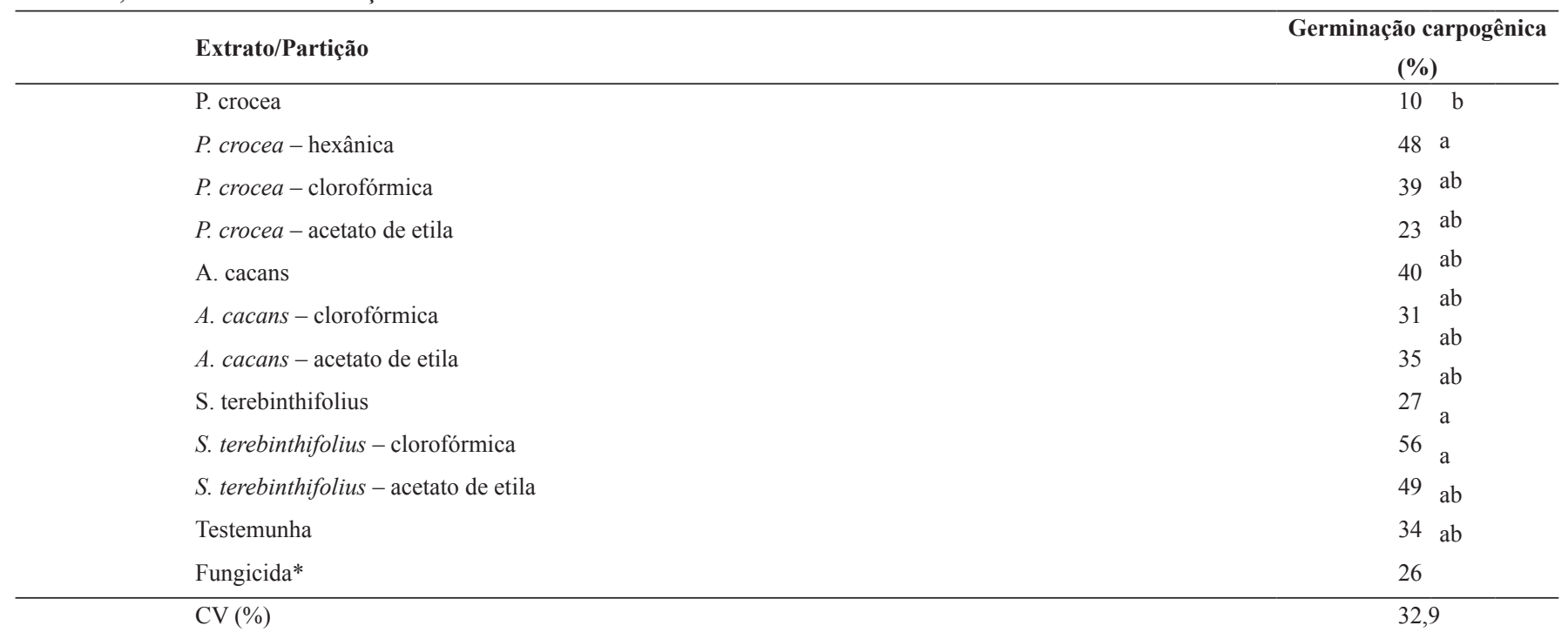

Médias seguidas pela mesma letra na coluna, não diferem entre si pelo teste de Tukey a 5\% de probabilidade. * Concentração de $75 \mathrm{~g}$ i.a. $\mathrm{L}^{-1}$ 
35 DI, houve formação de apotécios.

No ensaio em que os extratos e frações foram aplicados aos 30 dias após a instalação do ensaio, a germinação carpogênica foi 88 e $76 \%$ menor no tratamento $S$. terebinthifolius fração acetato de etila em relação à testemunha nas avaliações realizadas aos 32 e 39 DI, respectivamente (Tabela 5). Como os solventes utilizados na partição do extrato possuem diferentes polaridades, a fração acetato de etila possui, possivelmente, compostos não muito polares, como os flavonoides (7), o que justificaria a ação somente desta fração na supressão da germinação carpogênica.

Em todos os ensaios houve aumento constante da germinação carpogênica dos escleródios ao longo do tempo, para todos os tratamentos (Figuras 2 e 3 )

$\mathrm{O}$ extrato de $A$. cacans apresentou atividade fungicida sobre o patógeno provavelmente devido aos compostos químicos já identificados em extratos de plantas da família Annonaceae como alcalóides, flavonóides, flavononas, triterpenóides, esteróides, flavonas, flavonóis, xantonas, saponinas, taninos, entre outros (2). Os extratos hexânico e etanólico do caule de Annona sp. foram ativos contra $S$. sclerotiorum, demonstrando a atividade fungicida de compostos desta planta (1).

O extrato de S. terebinthifolius não foi eficiente em inibir a germinação do patógeno, mas a fração acetato de etila de $S$. terebinthifolius inibiu a germinação em mais de $90 \%$ em relação à testemunha, nas primeiras avaliações. Extratos de etanólicos de $S$. terebinthifolius inibiram o crescimento micelial de Colletotrichum gloeosporioides em concentrações superiores a $2 \%$, (9) e o extrato aquoso de $S$. terebinthifolius na concentração de $15 \%$ inibiu em $25 \%$ o crescimento micelial de Aspergilus nigrus e em $79 \%$ a esporulação deste patógeno (18), o que comprova o efeito fungicida dessa espécie. Desta forma, maiores estudos envolvendo esta espécie devem ser realizados com o objetivo de identificar os compostos com

Tabela 5. Germinação carpogênica (\%) de escleródios de S. sclerotiorum sob extratos e frações de extratos de espécies vegetais, aplicados aos 30 dias após instalação do ensaio, aos 32 e 39 dias de incubação.

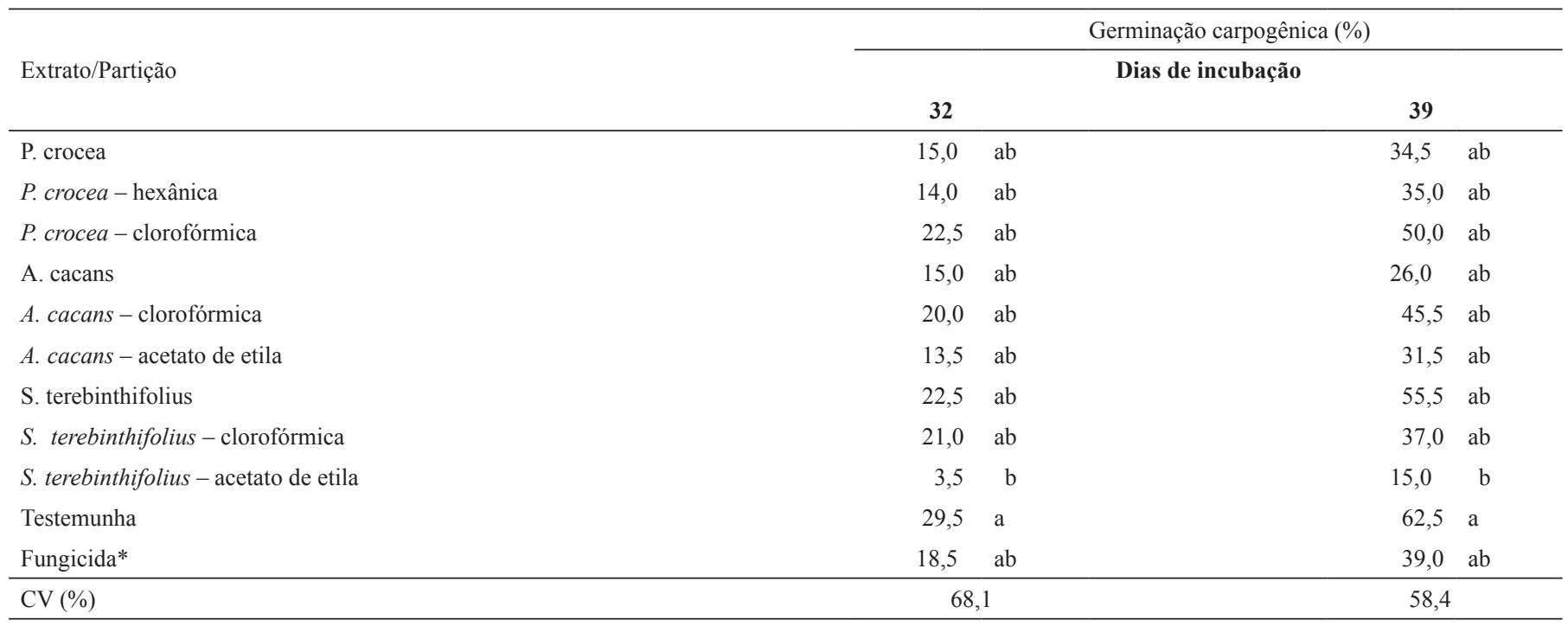

Médias seguidas pela mesma letra na coluna, não diferem entre si pelo teste de Tukey a 5\% de probabilidade. * concentração de $75 \mathrm{~g}$ i.a. $\mathrm{L}^{-1}$
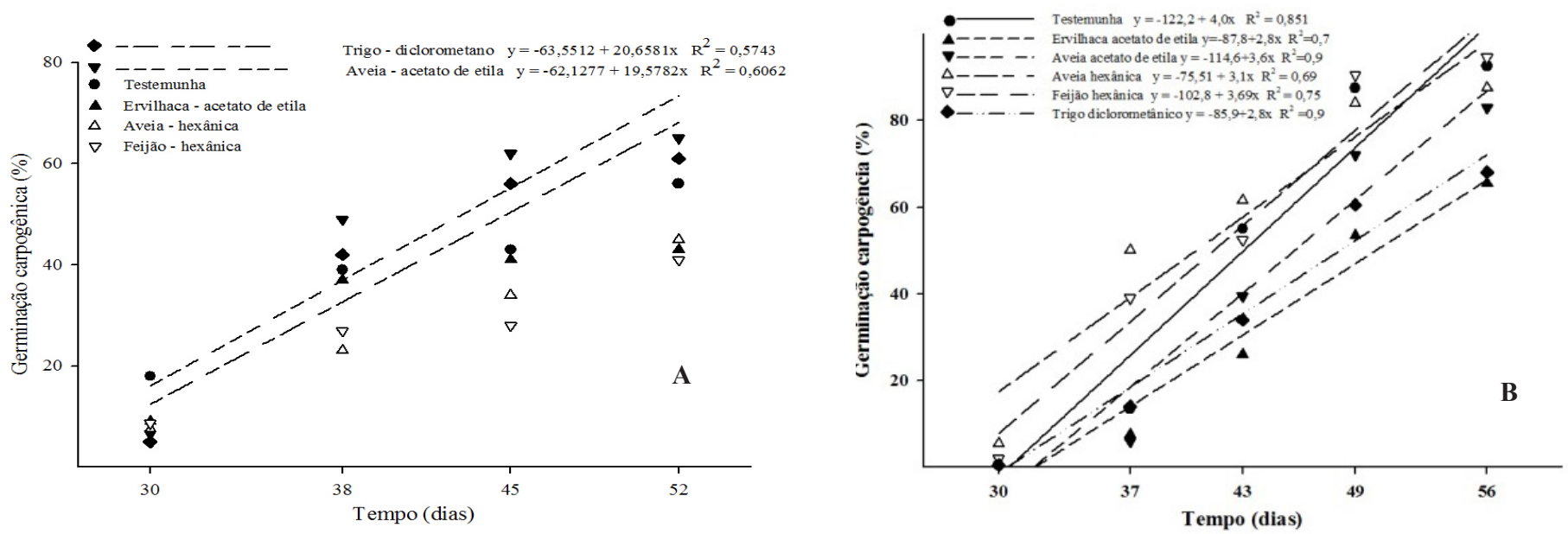

Figura 2. Germinação carpogênica(\%) de escleródios de S. sclerotiorum sob frações de extratos de plantas cultivadas, aplicadas no dia da instalação do ensaio (A) e 30 dias após a instalação (B) em função do tempo (dias), após a incubação. 

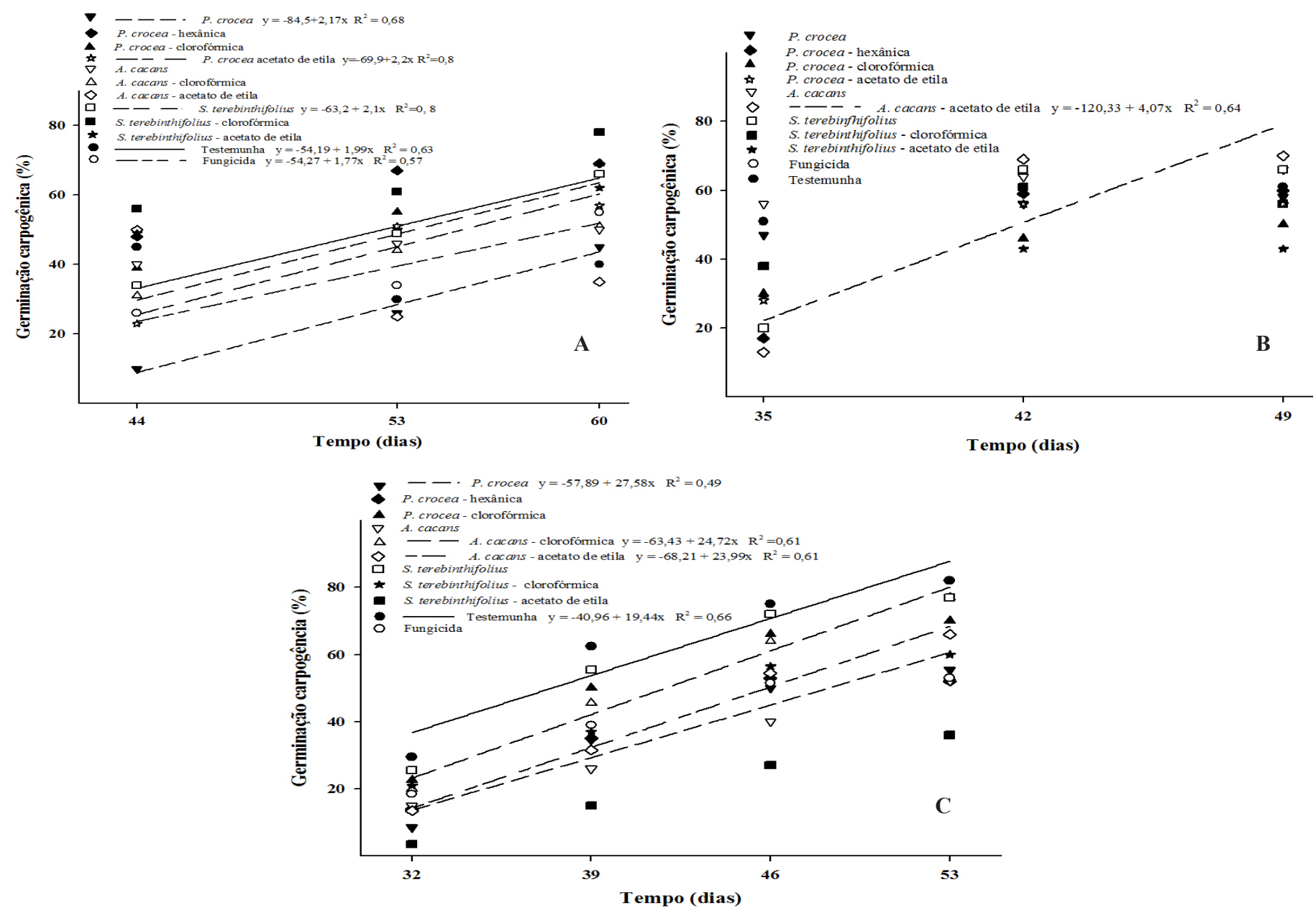

Figura 3. Germinação carpogênica (\%) de escleóridos de S. sclerotiorum sob extratos e frações de extratos vegetais, aplicados no dia da instalação do ensaio (A) e (B) e aos 30 dias após instalação (C) em função do tempo (dias), após a incubação.

ação fungicida presentes na fração acetato de etila, considerando que foi este composto o responsável pela maior supressão da germinação carpogênica de escleródios de $S$. sclerotiorum e não havia presença do solvente na fração.

\section{Avaliação de extratos vegetais sobre feijoeiro comum}

Para as características número de folíolos e fitotoxicidade não houve diferença entre os tratamentos. No segundo ensaio, além dos tratamentos do primeiro ensaio, foi acrescentado o óleo de S. terebinthifolius, mas nenhuma das características avaliadas apresentou diferença.

Plantas de feijoeiro, soja e trigo com oito dias foram expostas à exsudatos de raiz de sorgo, com o objetivo de testar sua ação alelopática sobre as plantas. Os autores constataram um leve sintoma visual de fitotoxicidade, mas não houve diferença entre os tratamentos sobre o peso de matéria seca das plantas, indicando que as plantas de feijão foram mais resistentes aos exsudatos do que plantas de soja e de trigo (17). Em experimento para avaliar os efeitos alelopáticos de extratos vegetais sobre germinação e crescimento inicial de feijoeiro, Faria et al. (4), verificaram que os extratos aquosos de milheto estimularam o comprimento de hipocótilo e o comprimento de radícula de feijão e diminuíram a porcentagem de germinação e a velocidade de emergência dessas plantas.
Plantas de feijoeiro que receberam aplicação de extratos de Nicotiana tabacum na concentração de $10 \%$ (p/v) e DalNeem (produto comercial a base de nim) na concentração de $10 \%(\mathrm{v} / \mathrm{v})$, apresentaram fitotoxicidade de 20 e $62 \%$, respectivamente, mas extratos de cinamomo e jambolão não causaram fitotoxicidade nas plantas. $\mathrm{O}$ peso médio das vagens foi reduzido em 30 e 35\% nos tratamentos a base de DalNeem e extrato de jambolão (3).

O presente trabalho corrobora com Neselho et al. (12), pois o extrato metanólico de S. terebinthifolius, as frações clorofórmica e acetato de etila e o óleo essencial dessa planta não causaram fitotoxicidade às plantas de feijão, na concentração utilizada.

Com base nos resultados obtidos, os escleródios de $S$. sclerotiorum apresentaram maior germinação carpogênica na proporção 1:1 e 1:2 do substrato solo:areia em relação aos demais tratamentos após 70 dias de incubação, houve menor germinação carpogênica sob as frações acetato de etila de ervilhaca e de $S$. terebinthifolius, quando estas foram aplicadas aos 30 dias após a infestação do substrato, a aplicação dos extratos e frações aos 30 dias após a instalação do ensaio apresenta maior efeito negativo sobre a germinação carpogênica dos escleródios do que aplicados no dia da infestação do ensaio. Os extratos e frações testadas não apresentaram fitotoxicidade ao feijoeiro comum. 


\section{AGRADECIMENTO}

A Professora Dra. Zefa Valdevina Pereira (UFGD), pela identificação dos materiais.

\section{REFERÊNCIAS}

1. Assis, M.F.O.; Silva, M.S.; Oliveira, L.D.; Rabello, A.R.; Alves, R.A.; Espindola, L.S.; Paula, J.E.; Vieira, E.A.; Lima, T.R.; Anjos, J.R.N.A. Fungos fitopatogênicos de soja e algodão são sensíveis a extratos orgânicos de planta nativa do cerrado do gênero Xylopia, família Annonaceae. In: Simpósio Nacional Cerrados, 9., 2008, Brasília, DF. Anais. Planaltina: Embrapa Cerrados, 2008. p.1-1.

2. Brito, H.O.; Noronha, E.P.; França, L.M.; Brito, L.M.O.; Prado, M.S.A. Análise da composição fitoquímica do extrato etanólico das folhas da $\mathrm{An}$ nona squamosa (ATA). Revista Brasileira de Farmácia, Rio de Janeiro, v.89, n.3, p.180-184, 2008.

3. Dequech, S.T.B.; Ribeiro, L.P.; Sausen, C.D.; Egewarth, R.; Kruse, N.D. Fitotoxicidade causada por inseticidas botânicos em feijão-de-vagem (Phaseolus vulgaris L.) cultivado em estufa plástica. Revista da FZVA, Uruguaiana, v.15, n.1, p.71-80, 2008.

4. Faria, T.M.; Gomes Junior, F.G.; Sá, M.E.; Cassiolato, A.M.R. Efeitos alelopáticos de extratos vegetais na germinação, colonização micorrízica e crescimento inicial de milho, soja e feijão. Revista Brasileira de Ciência do Solo, Viçosa, v.33, n.6, p.1625-1633, 2009.

5. Fontes, J.R.A.; Gonçalves, J.R.P.; Morais, R.R. Tolerância do feijão-caupi ao herbicida oxadiazon. Pesquisa Agropecuária Tropical, Goiânia, v.40, n.1, p.110-115, 2010.

6. Garcia, R.A.; Juliatti, F.C.; Barbosa, K.A.G.; Cassemiro, T.A. Atividade antifúngica de óleo e extratos vegetais sobre Sclerotinia sclerotiorum. Bioscience Journal, Uberlândia, v.28, n.1, p.48-57, 2012.

7. Gehrke, I.T.S. Estudo fitoquímico e biológico das espécies Schinus lentiscifolius, Schinus terebinthifolius, Schinus molle, Schinus polygamus (Anacardiaceae) do RS. 2012, 185f. Tese (Doutorado em Química) Centro de Ciências Naturais e Exatas - Universidade Federal de Santa Maria, Santa Maria.

8. Gonzaga, A.D.; Garcia, M.V.B.; Sousa, S.G.A.; Py-Daniel, V.; Correa, R.S.; Ribeiro, J.D. Toxicidade de manipueira de mandioca (Manihot esculenta Crantz) e erva-de-rato (Palicourea marcgravii St. Hill) a adultos de Toxoptera citricida Kirkaldy (Homoptera: Aphididae). Acta Amazonica, Manaus, v.38, n.1, p.101-106, 2008.

9. Lima, N.B.; Marques, M.W.; Caixeta, L.; Naue, C.R. Avaliação do extrato de aroeira (Schinus terebinthifolius Raddi) sobre o crescimento de Colletotri- chum gloeosporioides in vitro. In: Jornada de Ensino, Pesquisa e Extensão, 10., 2010, Recife. Anais. Recife: UFRPE, 2010. p.1.1

10. Monteiro, F.P.; Pacheco, L.P.; Lorenzetti, E.R.; Armesto, C.; Souza, P.E.; Abreu, M.S. Substrates and cover crop residues on the suppression of sclerotia and carpogenic germination of Sclerotinia sclerotiorum. Comunicata Scientiae, Piauí, v.3, n.3, p.199-205, 2012.

11. Mossini, S.A.G.; Kemmelmeier, C. A árvore Nim (Azadirachta indica A Juss): múltiplos usos. Acta Farmaceutica Bonaerense, Buenos Aires, v.24, n.1, p.139-148, 2005.

12. Nesello, M.A.; Pauletti, G.; Santos, A.C.A.; Atti-Serafini, L. Efeito alelot pático dos óleos essenciais de três espécimes de Schinus terebinthifolius sobre a germinação de Lactuca sativa L. In: Jornada Nacional de Iniciação Científica, 13., 2006, Florianópolis. Anais eletrônicos. São Paulo: SBPC/ UFSC, 2006. Disponível em: <http://www.sbpcnet.org.br/livro/58ra/JNIC/ RESUMOS/resumo_1885.html>. Acesso em: 05 jan. 2016.

13. Pansera, M.R; Vicenço, C.B.; Prancutti, A.; Sartori, V.C.; Ribeiro, R.T.S Controle alternativo do fungo Sclerotinia sclerotiorum (LIB.) De Bary causador da podridão de sclerotinia, com óleos essenciais e extratos vegetais. Revista Brasileira de Agroecologia, Rio de Janeiro, v.7, n.3, p.126-133, 2012.

14. Reis, E.M.; Casa, R.T.; Gava, F. Moreira, E.N.; Sachas, C. Indução da germinação carpogênica de escleródios de Sclerotinia sclerotiorum sob diferentes substratos. Revista de Ciências Agroveterinárias, Lages, v.10, n.2, p.145-150, 2011.

15. Silva, F.P.M.; Gavassoni, W.L.; Bacchi, L.M.A.; Garcez, F.R. Germinação carpogênica de Sclerotinia sclerotiorum sob diferentes resíduos e extratos de plantas cultivadas. Summa Phytopathologica, Botucatu,v.37, n.3, p.131-136, 2011.

16. Silva, L.J.; Silva, M.S.; Silva, L.N.; Rabello, A.R.; Alves, R.S.; Espíns dola, L.S.; Paula, J.E.; Vieira, E.A.; Lima, T.R.; Anjos, J.R.N. Fungos fitopatogênicos de soja são sensíveis a extratos orgânicos de planta "fruta-do-conde", nativa do cerrado do gênero Annona sp. (Família Annonaceae). In: Simposio Nacional Cerrado, 9.; Simpósio Internacional Savanas Tropicais, 2., 2008, Brasília, DF. Anais. Planaltina: Embrapa Cerrados, 2008. p.1-1.

17. Souza, C.N.; Souza, I.F.; Pasqual, M. Extração e ação de sorgolene sobre o crescimento de plantas. Ciência e Agrotecnologia, v. 23, n.3, p.331-338, 1999.

18. Souza, L.S.; Peixouto, Y.S.; Soares, A.C.F. Avaliação in vitro da atividade do extrato aquoso de aroeira (Schinus terebinthifolius Raddi) sobre Aspergillus niger, causador da podridão vermelha do sisal (Agave sisalana L.). In: Congresso Brasileiro de Micologia, 25., 2009, Porto de Galinhas. Anais. São Paulo: SBM, 2010. p.1-1.

19. Soylu, S.; Yigitbas,H.; Soylu, E.M.; Kurt, S. Antifungal effects of essens tial oils from oregano and fennel on Sclerotinia sclerotiorum. Journal of Applied Microbiology, Medford, v.103, n.4, p.1021-1030, 2007. 